\title{
Life after death in the ICU: detecting family-centered outcomes remains difficult
}

\author{
Katherine R. Courtright ${ }^{1,2^{*}}$, Dominique D. Benoit ${ }^{3}$ and Scott D. Halpern ${ }^{1,2}$
}

๑) 2017 Springer-Verlag GmbH Germany and ESICM

Family members of patients who die in the ICU experience significant and lasting psychological burdens, such as post-traumatic stress disorder (PTSD), anxiety, depression, and prolonged grief $[1,2]$. Among the many potential contributors to these adverse bereavement outcomes are the circumstances surrounding and processes of limiting life support. This hypothesis is supported by evidence that ICU deaths are commonly preceded by decisions to withdraw life support [3], and evidence that both ICU processes of care $[4,5]$ and behaviors of ICU clinicians $[1,6]$ near the end of life can influence family members' post-ICU psychological outcomes. Thus, uncertainty regarding which approaches to withdrawing mechanical ventilation are least distressing for patients and families $[7,8]$ represents an important area for rigorous investigation.

In this context, Reignier and colleagues performed a prospective observational cohort study to compare psychological symptoms in over 400 family members of patients who died after withdrawal of mechanical ventilation by immediate extubation vs. terminal weaning in 43 French ICUs [9]. Impressively, the authors were able to assess the primary endpoint of PTSD symptoms 3 months after death among over $95 \%$ of enrolled family members. Secondary endpoints included symptoms of anxiety, depression, and complicated grief among family members, symptom burdens of patients during the dying process, and strains on ICU staff.

The authors found no differences between groups in any of the psychological outcomes reported by family members at 3 months. This was a durable finding when adjusted for patient characteristics and center effects,

\footnotetext{
*Correspondence: katherine.courtright@uphs.upenn.edu

1 Palliative and Advanced IIlness Research (PAIR) Center, Perelman School

of Medicine at the University of Pennsylvania, Philadelphia, USA

Full author information is available at the end of the article
}

and at 6- and 12-month follow-up assessments. ICU staff experienced similar levels of job strain regardless of the withdrawal method chosen, with the exception of nursing assistants who reported less strain with immediate extubation. Patients in the immediate extubation group experienced more gasping and airway obstruction and received significantly lower doses, on average, of sedatives and analgesics compared to those undergoing terminal weaning. Given these results, the authors conclude that the choice between these two approaches to withdrawal of mechanical ventilation does not impact psychological symptoms among family members. They also suggest, and we agree, that standardized approaches to medication administration near the end of life may reduce patient suffering.

This study is innovative in empirically evaluating the impact of how mechanical ventilation is withdrawn on family-centered outcomes. It is also strengthened by the diverse sample of ICUs, and the outstanding follow-up rate. However, the ability to draw conclusions is tempered by the non-randomized design. Although the authors appropriately note that randomly assigning ICUs to an unfamiliar withdrawal method might engender low adherence to the assigned interventions, the observational design amounts to a comparison of withdrawal methods on family members who chose (or whose clinicians chose for them) a particular withdrawal method. Beyond this fundamental confound, the observational design also cannot adjust for all factors that may impact family members' psychological well-being after the death of a loved one in the ICU. For example, additional factors not evaluated, such as the quality of ICU physician communication [1], prior mental illness [10], and experience of additional stressors after the loss [2], have been associated with psychological symptoms in family members.

This suggests a perhaps more fundamental explanation for this study's largely null results. That is, despite

\section{Springer}


the unambiguous importance of assessing the impact of ICU care processes on family members' outcomes, the science of doing so is not yet up to the task. Scales assessing family-reported outcomes must be reliable, valid, and responsive. Although several measures have been found to be reliable and valid, responsiveness to ICUbased interventions has been a much more elusive goal. Few studies have found changes in the Impact of Events Scale (IES) $[4,5]$ among family members of critically ill patients, and even fewer have shown responsiveness of the Inventory of Complicated Grief (ICG).

This difficulty demonstrating effects of interventions on caregivers of ICU patients extends beyond psychological endpoints. For example, despite being rigorously developed and studied among more than 4000 deaths, few studies have found effects of interventions on family members' ratings of the Quality of Dying and Death (QODD) questionnaire [11], including a large randomized trial of a palliative care intervention [12]. If these and other scales are known to be reliable and to validly measure appropriate constructs, what might explain the discouraging results of studies designed to improve family-reported outcomes?

Beyond the usual explanations for null findings, such as truly ineffective interventions or failures to understand clinically important differences in the outcome measures and to power studies accordingly, we suspect a far greater challenge faces investigators seeking to improve family outcomes. Namely, there is likely great heterogeneity among family members, both in terms of their baseline psychological profiles and in their engagement in the processes of critical care delivery to their loved ones. Such heterogeneity makes it difficult, even in a large, randomized trial of a truly effective intervention, to find a "signal" amidst the "noise."

Indeed, in the present study only 3 in 5 relatives were involved in the decision to withdraw mechanical ventilation, and even fewer were involved in the choice between immediate extubation and terminal weaning. The majority of family members interviewed for this study were not in the patient's room at the time of extubation or initial ventilator weaning, and nearly half were not present at the time of death. Witnessing an intervention, and engaging in the associated decision-making and processes of care, may be required for family members to be impacted by such care. Although the results of the study by Reignier and colleagues did not change when adjusted for these measured aspects of family engagement, the mere presence of these measured forms of heterogeneity highlights the vast potential for unmeasured family-level factors that create unfavorable signal-to-noise ratios.

Surmounting this challenge will not be easy. But future efforts to improve family outcomes following critical care may be informed by corresponding efforts to improve outcomes for patients themselves, among whom considerable heterogeneity also exists. Specifically, the successful identification of interventions that improve family outcomes may require both large, pragmatic trials [13] and the development and incorporation of baseline indices of risk for adverse bereavement outcomes [14, 15].

\begin{abstract}
Author details
${ }^{1}$ Palliative and Advanced IIIness Research (PAIR) Center, Perelman School of Medicine at the University of Pennsylvania, Philadelphia, USA. ${ }^{2}$ Division of Pulmonary, Allergy, and Critical Care, Department of Medicine, Perelman School of Medicine at the University of Pennsylvania, Philadelphia, USA. ${ }^{3}$ Department of Intensive Care Medicine, Ghent University Hospital, Ghent, Belgium.
\end{abstract}

\section{Compliance with ethical standards}

Conflict of interest

On behalf of all authors, the corresponding author states that there is no conflict of interest.

Received: 18 July 2017 Accepted: 20 July 2017

Published online: 22 September 2017

\section{References}

1. Azoulay E, Pochard F, Kentish-Barnes N, Chevret S, Aboab J, Adrie C, Annane D, Bleichner G, Bollaert PE, Darmon M, Fassier T, Galliot R, Garrouste-Orgeas M, Goulenok C, Goldgran-Toledano D, Hayon J, Jourdain M, Kaidomar M, Laplace C, Larche J, Liotier J, Papazian L, Poisson C, Reignier J, Saidi F, Schlemmer B, FAMIREA Study Group (2005) Risk of post-traumatic stress symptoms in family members of intensive care unit patients. Am J Respir Crit Care Med 171:987-994

2. Siegel MD, Hayes E, Vanderwerker LC, Loseth DB, Prigerson HG (2008) Psychiatric illness in the next of kin of patients who die in the intensive care unit. Crit Care Med 36:1722-1728

3. Mark NM, Rayner SG, Lee NJ, Curtis JR (2015) Global variability in withholding and withdrawal of life-sustaining treatment in the intensive care unit: a systematic review. Intensive Care Med 41:1572-1585

4. Kentish-Barnes N, Chevret S, Champigneulle B, Thirion M, Souppart V, Gilbert M, Lesieur O, Renault A, Garrouste-Orgeas M, Argaud L, Venot M, Demoule A, Guisset O, Vinatier I, Troche G, Massot J, Jaber S, Bornstain C, Gaday V, Robert R, Rigaud JP, Cinotti R, Adda M, Thomas F, Calvet L, Galon M, Cohen-Solal Z, Cariou A, Azoulay E, Famirea Study Group (2017) Effect of a condolence letter on grief symptoms among relatives of patients who died in the ICU: a randomized clinical trial. Intensive Care Med 43:473-484

5. Lautrette A, Darmon M, Megarbane B, Joly LM, Chevret S, Adrie C, Barnoud D, Bleichner G, Bruel C, Choukroun G, Curtis JR, Fieux F, Galliot R, Garrouste-Orgeas M, Georges H, Goldgran-Toledano D, Jourdain M, Loubert G, Reignier J, Saidi F, Souweine B, Vincent F, Barnes NK, Pochard F, Schlemmer B, Azoulay E (2007) A communication strategy and brochure for relatives of patients dying in the ICU. N Engl J Med 356:469-478

6. McDonagh JR, Elliott TB, Engelberg RA, Treece PD, Shannon SE, Rubenfeld GD, Patrick DL, Curtis JR (2004) Family satisfaction with family conferences about end-of-life care in the intensive care unit: increased proportion of family speech is associated with increased satisfaction. Crit Care Med 32:1484-1488

7. Downar J, Delaney JW, Hawryluck L, Kenny L (2016) Guidelines for the withdrawal of life-sustaining measures. Intensive Care Med 42:1003-1017

8. Truog RD, Campbell ML, Curtis JR, Haas CE, Luce JM, Rubenfeld GD, Rushton CH, Kaufman DC, American Academy of Critical Care Medicine (2008) Recommendations for end-of-life care in the intensive care unit: a 
consensus statement by the American College [corrected] of Critical Care Medicine. Crit Care Med 36:953-963

9. Robert R, Le Gouge A, Kentish-Barnes N, Cottereau A, Giraudeau B, Adda M, Annane D, Audibert J, Barbier F, Bardou P, Bourcier S, Bourenne J, Boyer A, Brenas F, Das V, Desachy A, Devaquet J, Feissel M, Ganster F, Garrouste-Orgeas M, Grillet G, Guisset O, Hamidfar-Roy R, Hyacinthe A-C, Jochmans S, Jourdain M, Lautrette A, Lerolle N, Lesieur O, Lion F, Mateu P, Megarbane B, Merceron S, Mercier E, Messika J, Morin-Longuet P, Philippon-Jouve B, Quenot J-P, Renault A, Repesse X, Rigaud J-P, Robin S, Roquilly A, Seguin A, Thevenin D, Tirot P, Vinatier I, Azoulay E, Reignier $J$ (2017) Terminal weaning or immediate extubation for withdrawing mechanical ventilation in critically ill patients (the ARREVE Observational Study). Intensive Care Med. doi:10.1007/s00134-017-4891-0

10. Gries CJ, Engelberg RA, Kross EK, Zatzick D, Nielsen EL, Downey L, Curtis JR (2010) Predictors of symptoms of posttraumatic stress and depression in family members after patient death in the ICU. Chest 137:280-287
11. Curtis JR, Downey L, Engelberg RA (2013) The quality of dying and death: is it ready for use as an outcome measure? Chest 143:289-291

12. Curtis JR, Nielsen EL, Treece PD, Downey L, Dotolo D, Shannon SE, Back AL, Rubenfeld GD, Engelberg RA (2011) Effect of a quality-improvement intervention on end-of-life care in the intensive care unit a randomized trial. Am J Respir Crit Care Med 183:348-355

13. Ford I, Norrie J (2016) Pragmatic trials. N Engl J Med 375:454-463

14. Iwashyna TJ, Burke JF, Sussman JB, Prescott HC, Hayward RA, Angus DC (2015) Implications of heterogeneity of treatment effect for reporting and analysis of randomized trials in critical care. Am J Respir Crit Care Med 192(9):1045-1051

15. Kent DM, Hayward RA (2007) Limitations of applying summary results of clinical trials to individual patients: the need for risk stratification. J Am Med Assoc 298:1209-1212 